\title{
Research on New Thoughts and New Ways of Social Organizations Participating in Grassroots Social Governance
}

\author{
Donghai Jin ${ }^{1, *}$ \\ ${ }^{1}$ School of Marxism, Wuhan University of Technology, Wuhan, Hubei, China \\ *Corresponding author. Email: masonjin@163.com
}

\begin{abstract}
At present, China's reforms are gradually developing from the economic field to the social field, the way and structure of grassroots social governance are undergoing tremendous changes, the multiple interest relationships are complicated, and the gap of interests continues to widen. The previous model of government's unified organization of grassroots social governance in the era of planned economy can no longer meet the needs of social development in the new era. This requires China's grassroots social governance mechanisms to be continuously innovated, mobilizing the enthusiasm of various social organizations in accordance with the requirements of the real society, cultivating new ideas for social organizations to participate in social governance, providing new ways for social organizations to participate in social governance, and providing new vitality for the rejuvenation of the Chinese nation.
\end{abstract}

Keywords: social organization, grassroots social governance, practice, countermeasures

\section{INTRODUCTION}

With the in-depth development of economic globalization, social diversification, and cultural diversity, and China's undergoing unprecedented social changes, the resulting instability has taken on a new trend. How to solve many new challenges through effective social governance has become an urgent problem to be explored and solved. In particular, how social organizations can effectively participate in grassroots social governance is a new issue faced by innovative social governance. Through in-depth theoretical interpretation and practical research on this issue, it will help to further enhance the scientific level of social governance, bring social harmony and stability to a new level, and add new impetus to the construction of a safe China.

\section{PROBLEMS FACED BY SOCIAL} ORGANIZATIONS PARTICIPATING IN GRASSROOTS SOCIAL GOVERNANCE IN THE NEW ERA

Social organizations have achieved great results in participating in the practical activities of grassroots social governance, but due to various factors, there are still places that are not compatible with social development, and there is a large gap between the goal of building a harmonious society.

\section{A. The development of social organizations is uneven and weak}

After the rise of social organizations in China, they are constantly adapting to and satisfying the needs of different levels of grassroots social governance with their unique functions and roles. However, the uneven development of China's social organizations has undoubtedly become one of the main difficulties for its participation in grassroots social governance. First of all, from a historical point of view, the number of Chinese social organizations has indeed achieved rapid growth in recent years. According to statistics, the number of social organizations rose from 4,446 in 1988 to 762,000 in 2017. However, whether compared with the total population of more than 1.3 billion in China or compared with Western developed countries, the number of social organizations in China is significantly lower than the international level, with an average of more than 1,800 people per organization. Secondly, the quality and scale of social organizations can't be mentioned in the same breath with social organizations in most countries in the world. Thirdly, the urban and rural distribution of China's social organizations has shown an uneven development trend, with the eastern coastal areas developing rapidly, and the central and western regions developing slowly. Fourthly, community social organizations are not only small in number, but also weak. Fifthly, the industry distribution of social organizations is uneven. In some industries, social organizations are well-developed, and there are 
even repeated constructions, while in some fields, social organizations are not sound.

\section{B. The credibility of social organizations is weak and needs to be further improved}

The credibility of modern society plays a vital role in the sound development of any organization. Since the development of social organizations in China is still in its infancy, compared with the credibility of the government, social organizations are relatively weak and need to be improved. This has also become an obstacle to the benign and healthy development of social organizations, and the ability to absorb social resources will also be greatly reduced. The main manifestations are: on the one hand, the supervision mechanism is not sound. As a public welfare organization, social organizations need effective supervision and increase credibility. China's supervision of social organizations mainly comes from the social organizations themselves, government departments and the public. However, there is no effective supervision mechanism within social organizations; in addition to the annual unified inspection, government departments have not yet formed a social supervision and restriction system constructed by public supervision, news media and other public opinion supervision and independent thirdparty supervision. In addition, the poor self-discipline of social organizations has caused social supervision to be lagged behind, or even "to lose voice". Even if the lack of supervision is discovered and remedial measures are taken, the negative impact caused by this is irreparable. On the other hand, the transparency of information disclosure is insufficient, and the public lacks knowledge of information. Information disclosure is the strut of the credibility building of social organizations, and timely and true disclosure of information to the society is a problem that social organizations urgently need to solve.

\section{Social organizations have low ability to provide public services and can't be recognized by society and the government}

Due to the impact of the general environment, social organizations' low ability to provide services to the grassroots society has always been a shortcoming in their development. Internally, the management system is not perfect, the efficient financial mechanism, scientific decision-making mechanism and supervision and evaluation mechanism are not sound, and the professional quality and management level of the staff are not high. Externally, the legal system has not yet perfected system protection. The government provides better services to enterprises participating in social welfare undertakings, and puts forward feasible and effective policies in terms of tax reduction and the provision of a funding source system that supports their healthy development. This is also the main reason for the ineffectiveness of social organizations in resource integration and service provision. In particular, the grassroots social organizations bred in the transformation of Chinese society have developed rapidly and are numerous in number. Because of their grassroots status, their social and government recognition is low. At the current grassroots level in China, social governance plays an important role. Due to its small scale, shortage of funds, and low level, it is difficult to assume more responsibilities in public services and social management.

\section{The positioning of social organizations is not clear and lacks independence}

In China, the development of social organizations has not been completely treated rationally, and lacks the due independence and autonomy. The main manifestations are as follows: First, the grassroots government doesn't pay enough attention to the development of social organizations and their potential power to participate in social governance, with less cultivation and collaboration, and more instructions. Second, affected by all the ideological concept that the government does everything in the planned economy system, the government has always been regarded as the only subject to manage society, ignoring the role of social organizations in grassroots social governance. Third, some people believe that the core of social management is to maintain stability and strictly control those social organizations that exist independently of the government. Under the guidance of this thought, the government either ignores the development of social organizations, or establishes a strict access system for social organizations that do not obey instructions, or resolutely bans them, which greatly limits the development of social organizations. Fourth, the "dual management system" currently operated by the society makes social organizations reluctant to choose to comply with the competent authority and registration management authority, and the administrative color is too strong. In such a living environment, Chinese social organizations lack the corresponding sociality, independence, and autonomy from the establishment of the articles of association at the beginning of the establishment, to the subsequent operation and management, democratic decision-making, and personnel appointment and removal. Some social organizations have gradually degenerated into the "megaphone" of the government and the "vase" of civil society, losing their vitality and advantages in grassroots social governance.

\section{E. Social organizations have weak self-hematopoiesis ability as well as financial constraints}

Since social organizations have not yet developed to the point of maturity and perfection, especially due to 
the shortage of financial resources, they can't play the main role in the grassroots social governance and play the role of national governance assistants. In China, due to the absence of a strong and institutionalized funding source system for social organizations, economic constraints have always been a bottleneck problem that troubles the development and operation of social organizations in China.

The shortage of funds has also become an obstacle restricting its functioning. The current funds of social organizations are far from meeting their needs. The funding of social organizations mainly consists of a small amount of membership dues, social donations and government support, which is undoubtedly a drop in the bucket for the ever-increasing demand. The economic situation of government-run, semi-government-run and national associations is better. With the strong backing of the government, it has relatively easy channels to obtain financial support. For example, the China Charity Federation receives a certain amount of funding from the government every year. But even so, its financial constraints are still not optimistic. According to relevant surveys, in recent years, the proportion of its fundraising and donations from the international community has exceeded $60 \%$, while the domestic rich donate only $15 \%$. According to statistics, there are more than 10 million enterprises registered in the government's industrial and commercial departments, while the number of enterprises whose donations are recorded is less than 100,000 . It can be seen that the proportion of domestic enterprises and wealthy people participating in charity donations is relatively low, and the difficulty of fundraising for social organizations can be seen from this.

\section{COUNTERMEASURES FOR SOCIAL ORGANIZATIONS TO PARTICIPATE IN GRASSROOTS SOCIAL GOVERNANCE PRACTICES IN THE NEW ERA}

\section{A. Macro level}

1) Creating a good social governance atmosphere: In recent years, the Party Central Committee has elevated social governance to the level of modernization of the national governance system and governance capabilities. General Secretary Xi Jinping clearly stated at the Fourth Plenary Session of the 19th Central Committee: "To strengthen and innovate social governance, and improve the social governance system of party committee leadership, government responsibility, democratic consultation, social coordination, public participation, legal protection, and scientific and technological support." The Party Central Committee put forward the concept of innovative social governance, showing that the government is not the only subject of public power, and social organizations and individuals can also become the subject of public governance. Under the guidance of the goal of "people living and working in peace and contentment, social stability and order, and a higher level of safe China", they actively participate in grassroots social governance and jointly build a "social governance community where everyone is responsible, everyone does his duty, and everyone enjoys." The governance system shifts from a mere government's responsibility to a polynary social governance community where "everyone is responsible", which also conforms to the concept of mutual benefit and symbiosis between people in traditional Chinese culture. Although the Party Central Committee has proposed a new governance concept and a new governance system, it will take time for the new concept of social co-governance to be deeply rooted in the hearts of the people and to be actively implemented, and there is still a long way to go to build a new social governance pattern. It is prominently reflected in two levels: First, local governments at all levels have many limitations in providing public services, and the understanding of the advantages of social organizations participating in social governance not only needs to be further deepened, moreover, local governments at all levels have doubts about it, worrying that it will affect the reputation of the government. Second, for a long time, the government has undertaken the important task of social governance. Compared with the government, it has a profound influence and credibility among the people. However, the influence of social organizations on the people is relatively small, and their doubts are strong, and the lack of identity and trust is also inevitable.

Based on this, it is imperative to cultivate civic awareness, volunteerism and mutual assistance qualities, and provide fertile ground for social organizations. Over thousands of years of history, non-governmental public welfare undertakings have always been a weapon for maintaining social stability. Efforts should be made to take the opportunity to carry forward the historical and cultural tradition of helping others, strive to cultivate the people's spirit of volunteer service and the good quality of mutual assistance and symbiosis, and create a strong social atmosphere for the benign and healthy development of social organizations. A good social atmosphere doesn't happen overnight. It requires the unremitting efforts and cooperation of the government, citizens, enterprises, and social organizations. The government and all sectors of society should join hands and work together, vigorously advocate and actively promote, and take positive actions to invest in social organizations to participate in social governance, forming a demonstration effect, giving full play to the leading role of the new 
governance concept, and laying a foundation for social organizations to participate in social governance.

2) Creating a sound institutional governance environment: Compared with the mature and perfect institutional systems in Western countries, Chinese social organizations started late, and the relationship with the government is still in the exploratory stage. The social governance institution and system are constantly improving; to effectively promote the participation of social organizations in grassroots social governance, an institutional environment conducive to their participation must be created.

a) Laws and regulations: Through sorting and investigating the development history of social organizations in Western countries, it can be found that a sound legal system can provide institutional guarantees for the development of social organizations. In the transition of Chinese society to modernization, although the government has successively formulated some rules and regulations related to social organizations, the existing problems are prominently manifested in the following three levels: First of all, these regulations are formulated and promulgated by the administrative system of the State Council, and the laws formulated by the National People's Congress, the highest legislature, are lacking; secondly, the quantity is small and the content is not perfect; finally, the supporting policies are not sound enough, and there are some difficulties in operation. Therefore, on the basis of the existing legal system, it's necessary to further improve the corresponding laws and regulations, and clarify their rights, obligations, status, etc., to provide institutional guarantees for social organizations to participate in social governance.

b) The relationship between the government and social organizations: In the tide of marketization, social organizations came into being in order to satisfy the diverse interests of the people. In many public service areas, they can act as a good helper and partner of the government, improve public governance more effectively, and more effectively satisfy the different demands of the people. Due to the constraints of many factors, social organizations that are still in the initial stage of development have limited space for independent activities, and lack of social resources, shortage of funds, insufficient talents, and small-scale problems have become common phenomena in social organizations. Therefore, the government plays the role of mastering the direction and steering the development of social organizations, rather than controlling them everywhere and restricting their development. It's needed to establish a partnership between the two parties in terms of projects, services, funds, information, etc., create a relaxed development environment and space, and give preferential tax reduction and exemption policies in terms of taxation. The establishment of a partnership between the government and social organizations plays an important role in the development of social organizations, and provides institutional guarantees for the independence, professionalism, and healthy development of social organizations from the institutional mechanism.

3) Establishing a sound supervision mechanism: For any social organization, a sound supervision and management system and high-level management quality are the only way to maintain a healthy operation and improve social reputation. Supervision and management of social organizations in Western countries has always played an irreplaceable role in the process of operation. Social organizations regulate their behaviors by improving the supervision and management system, and provide effective supervision guarantee for social organizations to participate in social governance. At present, the supervision and management responsibilities of Chinese social organizations are the responsibility of their administrative authorities and business authorities. In the tide of China's social transformation and the market economy, many social organizations have sprung up like bamboo shoots after a rain, and are actively involved in grassroots social governance. The limited dual supervision under the existing system has lagged behind the needs of the times. Just as "stones from other mountains can be used for jade", Japan and other Western countries' perfect and mature social organization supervision and management experience provides useful enlightenment for China. It is necessary to build a diversified supervision system including government supervision, third-party evaluation, public opinion supervision, and public supervision, so as to provide a guarantee for the maturity and improvement of China's social organization supervision system.

a) The main experience of Japanese social organizations participating in grassroots social governance: First, it's needed to establish a good relationship of mutual trust between the government and social organizations. Without credit, one has no standing room; without credit, one can't move forward. The good trust relationship between the government and social organizations promotes the participation of social organizations in grassroots social governance. The local government needs to decide on themes such as "building a vibrant hometown" and "building a safe and secure city" in accordance with local conditions. It is necessary to build a cooperative operation model for local governments, NPOs (Non Profit Organization) and citizens. The three parties have their own division 
of labor and their respective responsibilities. NPOs and local government jointly set up a project team. The government helps NPOs to work on solving the project, and publishes a special news bulletin to advertise it, which encourages and promotes citizens' participation in NPOs' activities.

Second, there are close ties between social organizations and the grassroots. Non-governmental organizations composed of local residents can not only discover relevant life problems in time, but also provide feedback to the government and put forward effective countermeasures, and even provide early warning to the government and provide necessary assistance for the implementation of government decisions and supervision. At the same time, social organizations organize and provide services close to the lives of citizens. According to the characteristics of the community and the needs of residents, services such as prevention of domestic violence, prevention of Alzheimer's disease, nutrition education, and legal consulting assistance can be provided.

Third, all sectors of society strongly support the development of social organizations. There are NPO support centers established with the support of the government, large financial clique and the general public throughout Japan. These non-governmental organizations can provide various daily services such as venues, equipment, materials, and consultations for groups or individuals to carry out activities.

b) Enlightenment of Japanese social organizations participating in social governance: From the government level, it's necessary to first recognize its own limitations, and promote the development of social organizations and support social organizations to participate in grassroots social governance as the work goals of local governments at all levels in the process of functional transformation; secondly, it must have a clear role positioning and division of labor with social organizations to build a partnership between the government and social organizations; thirdly, it's necessary to provide institutional guarantees for the sound development of social organizations from the institutional and legal aspects; finally, it's needed to improve the supervision mechanism of social organizations.

From the perspective of social organizations themselves, first of all, it's necessary to improve internal rules and regulations, strengthen management and work effectiveness, and increase public trust; secondly, it's necessary to continuously expand service functions and service areas to meet the service needs of different members of the society; finally, it's needed to openly and transparently participate in social governance and accept the supervision of the government and the general public.
For members of society, first, they need to have a passion for active participation in social welfare activities and grassroots governance activities, and create an environment for the public to participate in social governance. Second, it's needed to actively publicize the effectiveness of citizens' participation in social governance and form a demonstration effect.

\section{B. Micro level}

The participation of social organizations in grassroots social governance is not only related to government support, but also closely related to their self-care, management, and credibility building capabilities.

1) Increasing the number of social organizations: There is a big gap between China's social organizations and developed countries in terms of total amount and per capita. In Western countries, there is one social organization for every 100 people. As of the end of 2017, there were 762,000 social organizations in China, with an average of 1,837 people with only one organization, a gap of more than eight times compared with Western countries. The insufficient number of social organizations has led to an insufficient number of social services provided by them. The State Council and local governments should encourage citizens to apply for social organizations and social enterprises in terms of policies. For existing social organizations, policy and financial support must be given.

2) Promoting the rational distribution of social organizations: Social organizations in China show a trend of uneven development in urban and rural areas. The development of the western region lags far behind the eastern region. Even in the eastern coastal areas, the gap in the development of urban and rural social organizations is very obvious. Due to the large gap in social development between urban and rural areas, the level of development of urban social organizations is far from comparable to that of rural areas. Urban social organizations develop rapidly and activities are concentrated, and public awareness is high; in poor villages, with the exception of poverty alleviation and development, education and health, there are very few local social organizations. In terms of fields, social organizations have developed rapidly in areas with relatively loose policies and easy access to resources, and vice versa. Therefore, the government provides support for the development of social organizations in the central and western regions and remote rural areas at the policy level, and provides necessary support to social organizations in the fields of employment, social security, housing security, and labor rights protection. 
3) Promoting the construction of social
organization management capabilities: The improvement of management ability is realized through management structure, personnel quality and perfect rules and regulations.

a) Effective management structure: The core of the management structure that maintains the efficient operation of social organizations is composed of the board of directors, the president, and the executive vice president. Except for the executive vice president who is responsible for the daily management of full-time personnel, the other personnel are all part-time, whose main responsibility is to raise funds and conduct performance evaluations.

b) High-quality professional staff: Having highquality professional staff is an important indicator to measure the quality of social organizations. It can not only improve the appearance of social organizations, but more importantly, it will inevitably greatly improve their work efficiency. Talent is the most important resource in the 21 st century, and plays an important role in social organizations in market competition. Therefore, it is necessary to create an environment that values talents, remove obstacles to the introduction of talents, and at the same time focus on cultivating talents from within, and gradually form a high-level professional talent team.

c) Sound rules and regulations: It is necessary to establish a modern corporate governance structure with checks and balances of power to ensure that different management institutions such as the council and the board of supervisors can operate efficiently on the road of standardization and rule of law. It is also necessary to continuously improve the rules and regulations necessary for internal governance, and improve the internal incentive and restraint mechanisms.

4) Promoting the building of the credibility of social organizations: "People can't stand without credit, a industry will not prosper without credit, and a country will decline without credit". The credibility of social organizations is the lifeline of their survival and development, and also an important indicator for measuring the development of public welfare and charity. Whether information is open and transparent relates to an important criterion for the credibility of social organizations to win the trust of the people. To enhance public credibility, it's necessary to first develop an organizational system that combines accountability and transparency; second, it's needed to regularly disclose financial information such as revenue and expenditure, budget, etc., so that the public can understand and win the trust of the public. Third, social organizations should formulate policies to monitor dereliction of duty or incidents to prevent internal illegal behaviors or dereliction of duty, and actively invite the government and third-party departments to supervise the construction and development of their units.

In the process of social transformation, various interest demands emerge one after another, and the influence of social organizations is increasing day by day. Social organizations can resolve social conflicts, provide public services, accumulate social funds, participate in grassroots social governance, integrate social resources, etc., to help the government solve problems, meet the various interests of the people, and maintain social stability. With the rise of China, for China, which is getting closer to the center of the world stage, social development opportunities and challenges coexist. There are many urgent problems need to be solved in the social field. Due to pressures of limited financial resources and changing government functions, it is somewhat incapable of satisfying the various interests of the people and social public services. The report of the 19th National Congress of the Communist Party of China emphasized the need to mobilize the enthusiasm of various social organizations, cultivate new ideas for social organizations to participate in social governance, and provide new ways for social organizations to participate in social governance. The participation of social organizations in social governance in the new era will usher in a broad space for development, providing new vitality for the realization of national rejuvenation.

\section{Conclusion}

In short, China is in a critical period of transforming government functions and building a "small government-big society". Studying the participation of social organizations in community governance provides theoretical support for deepening the transformation of Chinese government functions, which is of great significance to give full play to the role of social organizations, to realize the benign interaction of government governance and social adjustment, residents' autonomy, and to create a new pattern of grassroots social governance featuring co-construction, sharing and co-governance.

\section{References}

[1] [US] Lest Salamon. Research on the government's purchase of public services from social organizations: an analysis of China and global experience $[\mathrm{M}]$. Wang Puqu. Beijing: Peking University Press, 2010. (in Chinese)

[2] Chen Lianfeng. Promoting the development of social organizations based on social governance [J]. Fujian Forum (Humanities and Social Sciences Edition), 2014(11). (in Chinese) 
[3] Li Liguo. Innovating social governance system [J]. Qstheory, 2013(12). (in Chinese)

[4] Kong Jinping. Social organizations in the national governance system: western theory and Chinese experience [J]. Journal of Tianjin Administration Institute, 2017(7). (in Chinese)

[5] Wang Ming. A preliminary study on the social co-governance system [J]. Administrative Tribune, 2014(5). (in Chinese)

[6] Ye Shuzong. The changes in national governance models [J]. Journal of Shanghai Business School, 2007(2). (in Chinese) 